\title{
Hepatocellular carcinoma and type 2 diabetes mellitus: cytokeratin 8/18 expression in hepatocellular carcinoma and glycogen-storing hepatocytes
}

\author{
Kunio Takegoshi", Eikichi Okada², Qin Su${ }^{3}$ \\ ${ }^{1}$ Takegoshi Internal Medicine Clinic, Takaoka, Toyama 933-0014, Japan. \\ ${ }^{2}$ Pathological Division of Takaoka City Hospital, Takaoka, Toyama 933-8550, Japan. \\ ${ }^{3}$ Cell Marque, Sigma-Aldrich, Rocklin, CA 95677, USA.
}

\section{Corresponding Author:}

Dr. Kunio Takegoshi, Takegoshi Internal Medicine Clinic, 377-7 Nomura, Takaoka, Toyama 933-0014, Japan. E-mail: kunio@takegoshi.jp

Received: 04-07-2016; Accepted: 08-07-2016

Sir,

We have reported two patients with hepatocellular carcinoma (HCC) and type 2 diabetes mellitus (T2DM), who showed abundant glycogen in their liver parenchyma but a marked reduction of glycogen content in HCC. ${ }^{[1]}$ It was suggested that the latter was associated with appearance of a Warburg type glycolysis ${ }^{[1]}$ and discussed in some detail. ${ }^{[2]}$

Cytokeratins (CKs), the intermediate filament (IF) proteins of epithelia, are sub-divided into type I (CK9-20) and type II (CK1-8) and expressed as type I/II pairs in a cell differentiation manner. In adult liver, hepatocyte IF comprise only CK8/18. ${ }^{|3|}$ CK8/18 expression in normal and diseased liver has been reported, including positive expression in alcoholic steatohepatitis (ASH) and/or non-alcoholic steatohepatitis (NASH) and HCC. ${ }^{[3]}$

We examined the expression of CK8/18 in the liver to investigate cytoskeletal alterations in hepatocytes, possibly related to changes in hepatocellular glycogen content during hepatocarcinogenesis. Our studies revealed that immunoreactivity for CK8/18 was reduced or frequently even negative in glycogen-rich hepatocytes of background liver [Figure $1 \mathrm{~b}$ and $\mathrm{d}$ ], but moderately positive in normal hepatocytes and glycogen-poor cells in HCC [Figure 1a, c, e and f]. Overexpression of CK8/18, as Malory Denk bodies, which are hallmark lesions in ASH and $\mathrm{NASH}^{\left[{ }^{[3]}\right.}$ was not detected [Figure $1 \mathrm{~b}$ and $\mathrm{d}$ ]. The

\begin{tabular}{|l|c|}
\hline \multicolumn{2}{|c|}{ Access this article online } \\
\hline \multirow{2}{*}{ Website: } & Quick Response Code \\
http://www.hrjournal.net/ & \\
\hline & \\
DOI: &
\end{tabular}

results provide evidence for reduced to negative CK8/18 expression in glycogen-rich hepatocytes.

The mechanism of alteration of CK8/18 expression in glycogen-rich hepatocytes has not been elucidated. Su et al. ${ }^{[4]}$ demonstrated that CK8/18 expression was reduced in excessively glycogen-storing (glycogenotic) clear hepatocytes, which also showed a relative reduction of cytoplasmic organelles as demonstrated by electron-microscopic studies. Given simple CK8/18 expression patterns, hepatocytes are sensitive to alterations of cytokeratin architecture. ${ }^{[3]}$ Using hepatic cell culture systems, Mathew et al. ${ }^{[5]}$ reported recently that CK8/18 is involved in the interplay between glucose utilization and insulin signaling. The authors demonstrated that insulin stimulates glucose uptake, glucose-6-phosphatase formation, lactate release, and glycogen formation in hepatocytes via the PI-3 kinase dependent signaling pathway, and that CK8/18 IF loss makes them more efficient glycogen producers. ${ }^{[5]}$ This is in line with the notion that an insulinomimetic effect of oncogenic agents is responsible for the preneoplastic hepatocellular glycogenosis, ${ }^{[2]}$ which is associated with a reduced or negative expression of CK 8/18 in glycogenotic clear cells appearing in chronic human and woodchuck hepadnaviral infection. ${ }^{[4]}$ CK8/18 immunohistochemistry may allow distinct recognition of the glycogen-rich hepatocytes as shown in glycogenotic clear cells under various conditions. ${ }^{[4]}$

This is an open access article distributed under the terms of the Creative Commons Attribution-NonCommercial-ShareAlike 3.0 License, which allows others to remix, tweak, and build upon the worknon-commercially, as long as the author is credited and the new creations are licensed under the identical terms.

For reprints contact: service@oaepublish.com

How to cite this article: Takegoshi K, Okada E, Su Q. Hepatocellular carcinoma and type 2 diabetes mellitus: cytokeratin 8/18 expression in hepatocellular carcinoma and glycogen-storing hepatocytes. Hepatoma Res 2016;2:229-30. 
(a)

(b)

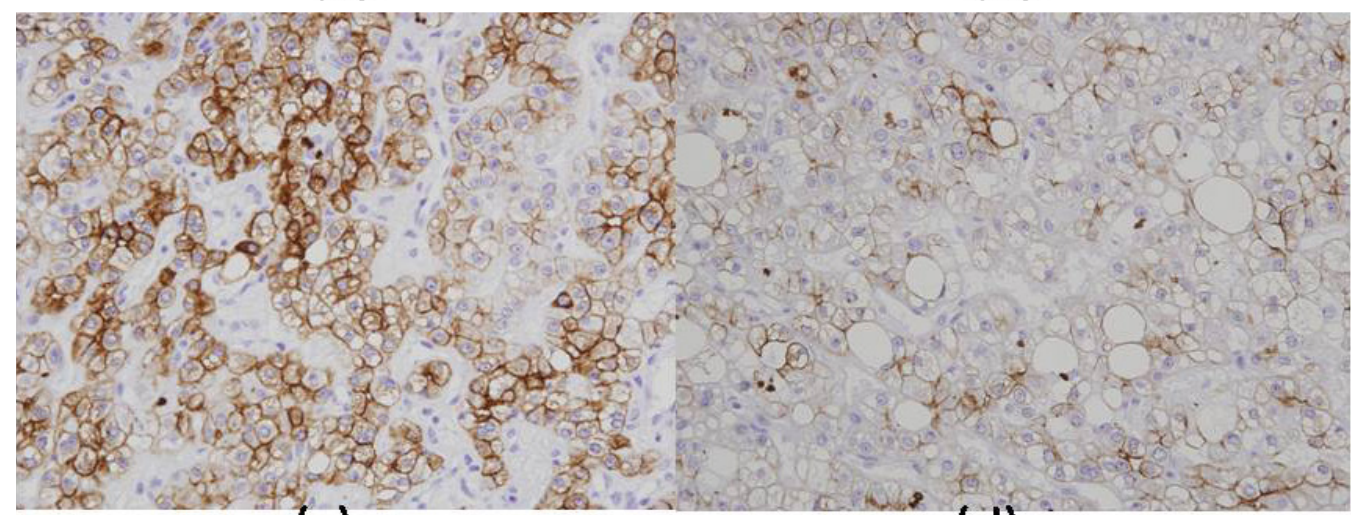

(c)

(d)

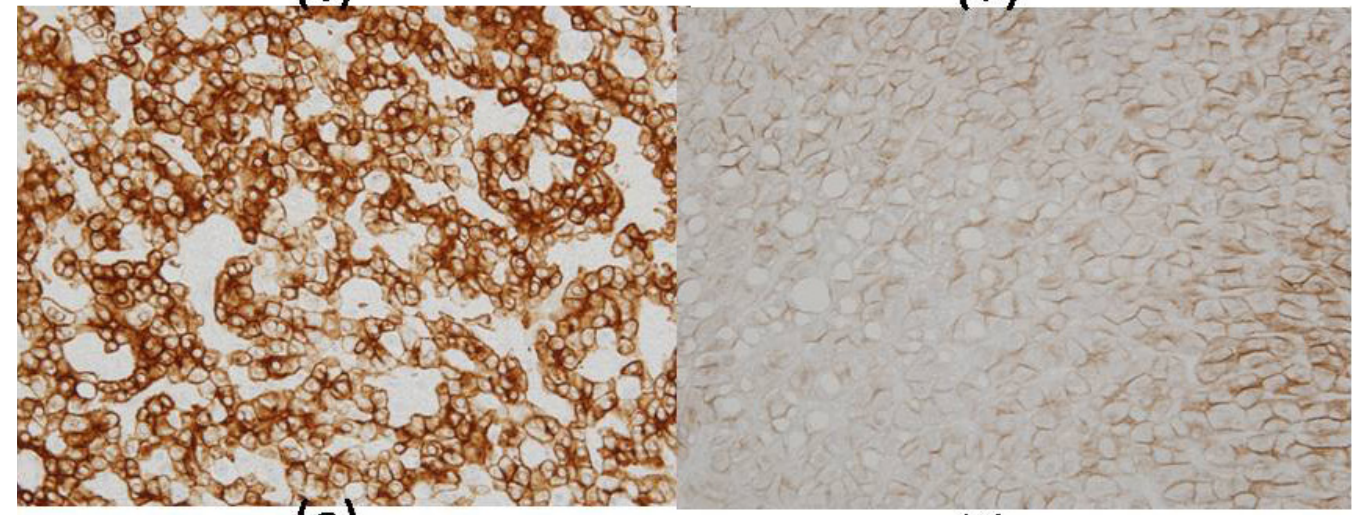

(e)

(f)

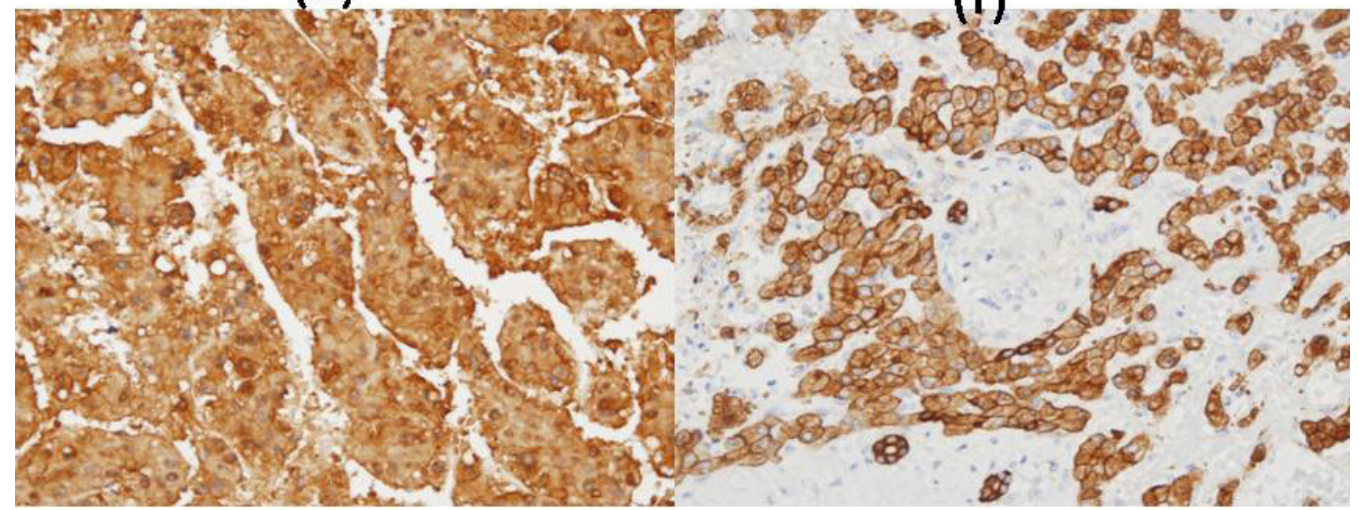

Figure 1: CK8/18 expression in hepatocellular carcinoma (a; case 1, c; case 2, e; control) and background liver (b; case1, d; case 2, f; control), demonstrated with mouse monoclonal antibodies B22.1/B23.1 (Cell Marque, USA) and visualized using the Envision method (Dako) (a-f, $\times 400)$. Control (a 79-year-old male, moderately differentiated adenocarcinoma in background of nearly normal liver)

\section{Financial support and sponsorship} Nil.

\section{Conflicts of interest}

There are no conflicts of interest.

\section{REFERENCES}

1. Takegoshi K, Okada E, Nomoto K, Nobata K, Sawasaki T, Terada M, Terakawa H, Kobayashi T, Yabushita K, Sugimoto T, Terahata S. Hepatocellular carcinoma and type 2 diabetes mellitus: two cases highlighting changes in tumor glycogen content. Hepatoma Res
2016;2:26-30.

2. Bannasch P, Klimek F, Mayer D. Early bioenergetic changes in hepatocarcinogenesis: preneoplastic phenotypes mimic responses to insulin and thyroid hormone. J Bioenerg Biomembr 1997;29:303-13.

3. Strnad P, Paschke S, Jang KH, Ku NO. Keratins: markers and modulators of liver disease. Curr Opin Gastroenterol 2012;28:209-16.

4. Su Q, Zerban H, Otto G, Bannasch P. Cytokeratin expression is reduced in glycogenotic clear hepatocytes but increased in ground-glass cells in chronic human and woodchuck hepadnaviral infection. Hepatology 1998;28:347-59.

5. Mathew J, Loranger A, Gilbert S, Faure R, Marceau N. Keratin 8/18 regulation of glucose metabolism in normal versus cancerous hepatic cells through differential modulation of hexokinase status and insulin signaling. Exp Cell Res 2013;319:474-86. 